\title{
Physical activity barriers according to social stratification in Europe
}

\author{
Antonio Moreno-Llamas ${ }^{1} \cdot$ Jesús García-Mayor ${ }^{1} \cdot$ Ernesto De la Cruz-Sánchez $^{1}$
}

Received: 19 March 2020/Revised: 31 July 2020 / Accepted: 20 September 2020/Published online: 28 September 2020

(C) Swiss School of Public Health (SSPH+) 2020

\begin{abstract}
Objectives To analyse relationships of social stratification on physical activity (PA) prevalence and barriers in the European population.

Methods Data were retrieved from Eurobarometer 88.4, a cross-sectional survey conducted in 2017 with 28,031 over 15-year-old inhabitants of the European Union. PA prevalence was calculated along with the probability to be physically inactive by social stratification. Logistic regressions were run in the inactive population to show the social class effect on each barrier adjusted by sociodemographic factors employing a propensity score matched method.

Results Low social class presented higher inactivity prevalence $(43.11 \%)$, whilst the high social class reported the lowest prevalence (23.30\%). Also, the low (OR 0.52; 95\% CI 0.47-0.58) and middle (OR 0.71; 95\% CI 0.64-0.79) social classes were less likely to be active compared to high social class. In the inactive population, the low social class had mostly higher odds to report each barrier.

Conclusions Social class is a relevant factor for low PA, with more barriers in the lower social classes. Public health institutions should implement strategies on more influential PA barriers and disadvantaged social groups.
\end{abstract}

Keywords Physical activity $\cdot$ Barriers $\cdot$ Social determinants $\cdot$ Social class $\cdot$ Lifestyle

\section{Introduction}

Physical activity (PA) practice has been demonstrated have benefits for population health (Rhodes et al. 2010; Hallal et al. 2012; Kohl et al. 2012; Wilmot et al. 2012). Thus, the World Health Organization (WHO) established global PA recommendations in order to assess, monitor, and promote an active lifestyle in the overall population (World Health Organization 2010). Nonetheless, worldwide PA prevalence-the population proportion that meets the WHO's

Electronic supplementary material The online version of this article (https://doi.org/10.1007/s00038-020-01488-y) contains supplementary material, which is available to authorized users.

Ernesto De la Cruz-Sánchez

erneslacruz@um.es

Antonio Moreno-Llamas

antonio.moreno13@um.es

Jesús García-Mayor

jesus.garcia9@um.es

1 University of Murcia, San Javier Campus, C/Santa Alicia s/n, 30720 Santiago de la Ribera, Murcia, Spain
PA recommendations-is widely heterogeneous and has diminished across the years: in 2010, $23 \%$ of adults aged 18-65 were considered inactive (Rhodes et al. 2010; Guthold et al. 2018); in 2016, the inactivity prevalence continues to rise, and the $27.5 \%$ of adults worldwide were classified as inactive. Because of this, physical inactivity has been declared a global pandemic and a serious public health issue worldwide (Kohl et al. 2012; Guthold et al. 2018).

Lifestyle behaviours, such as PA, could be influenced by attributes such as age, gender, social class, educational level, employment, income, resident place, and social support, among others (Denman 1998). Social, political, and cultural factors determine lifestyle behaviours, living conditions, and individual wellbeing, ultimately affecting health (Bauman et al. 2012; Rutter et al. 2019). In the last two decades, social disparities have risen across the EU, changing health-related behaviours among the population in complex and causal relationships (Huijts et al. 2017). These social determinants and socioeconomic domains of health have provided relevant and further information to understand most health-related behaviours, wellbeing, and health, as well as its underlying factors among the European population (Huijts et al. 2017). However, some of the 
social determinants of health-related behaviours have not been thoroughly investigated (O'Donoghue et al. 2018).

There is an important and emerging set of studies suggesting that these social inequalities and factors might affect PA (O'Donoghue et al. 2018) As such, those disadvantaged and deprived population groups might report lower PA level by experiencing greater difficulties, limitations, impediments, and less accessibility; they encounter more barriers to an active lifestyle (Costello et al. 2011; Gray et al. 2016). However, according to recent detailed reviews, current evidence on the social determinants of PA behaviour across the life course remains unclear and insufficient due to a limited number of primary studies, weak research designs, small or non-representative sample sizes, and methodological shortcomings (O'Donoghue et al. 2018). Therefore, here we study the social inequalities in PA prevalence using a large and representative sample of European population older than 15, and how the European population differs in their self-perceived PA barriers across social stratification.

\section{Methods}

The present study was conducted according to the STROBE Statement for cross-sectional studies (STROBE Statement 2008).

\section{Data}

Data were retrieved from Eurobarometer 88.4 (European Commission 2018), a cross-sectional survey of over 15 years European population among the respective nationalities of the 28 European Union Member States. A total of 28,031 responders participated in the study, approximately 1000 sample size per country, collected between 2 December and 11 December 2017.

A multi-stage random sampling method was used for this survey. In each country, several sampling points were systematically drawn with a proportional probability to population size and density by individual unit and type of area stratification. In all countries gender, age, region, and size of the locality were introduced in the iteration procedure. In each household, the respondent was selected at random, and all interviews were conducted face-to-face in the appropriate national language by trained interviewers.

\section{Measures}

\section{PA assessment and classification}

To assess the total amount of PA, the Short version of the International Physical Activity Questionnaire (IPAQ) was used (Craig et al. 2003). The IPAQ is a valid and reliable questionnaire to assess PA levels in large populations. Thus, IPAQ is divided into three components according to different intensity types of exercise as vigorous, moderate, and walking in the last 7 days. Time spent per day of each intensity was reported into six ranges: zero, less than $30 \mathrm{~min}$, from 30 to $60 \mathrm{~min}$, from 60 to $90 \mathrm{~min}$, from 90 to $120 \mathrm{~min}$, and more than $120 \mathrm{~min}$. Then, it was estimated through median values of its intervals, and for last range (more than $120 \mathrm{~min}$ ), a value of $135 \mathrm{~min}$ was used.

The European Population PA was classified into individuals who meet or do not meet the WHO PA recommendations (World Health Organization 2010), being considered "physically active" or "physically inactive", respectively. To meet such PA guidelines, individuals must achieve at least one of the following assumptions: (1) 150 min of moderate-intensity PA per week; (2) 75 min of vigorous-intensity PA per week; or (3) any equivalent combination.

\section{Social stratification}

Social class was sorted into seven categories according to occupational classification explained elsewhere (Chan and Goldthorpe 2007), being category I Professionals and managers with higher grade and category VII non-skilled manual workers. Given the few samples in several categories, the number of categories was reduced to three: these high, middle, and low social class (Domingo-Salvany et al. 2013).

\section{Physical activity barriers}

Physical inactivity could be due to several factors, such as economic, sociological, environmental, health-related, and psychological factors. Thus, nine PA barriers were included to provide a wide perspective of physical inactivity triggers: "No time", "Too expensive", "Competitivity", "No infrastructure", "Disability/Illness", "No friends", "Feel discriminated", "Lack of motivation", and "Risk of injuries". To survey PA barriers, a multi-choice question was used: "What are the main reasons currently preventing you from practising sport more regularly?". These PA barriers have been described in previous studies (Reichert et al. 2007; Cerin et al. 2010; Costello et al. 2011; Kelly et al. 2016).

\section{Statistical analyses}

First, descriptive and covariate-adjusted binomial logistic regression were performed in the overall sample between physically inactive and active sample by social stratification and others sociodemographic confounders. 
Subsequently, propensity score matching was only run in the physically inactive population $(n=9829)$ for each PA barrier, excluding 17,415 participants who met the WHO's PA recommendations. The propensity score matching method is mostly used to control confounders to aim to reduce bias in observational studies (Rubin and Rosenbaum 1983). This statistic method matches cases (perceive a PA barrier) and controls with a similar propensity score. Propensity score represents the likelihood to be a case in a range from 0 to 1 based on the employed confounders (Imai and Ratkovic 2014). Gender, age, resident place (rural, small urban, and large urban), and the difficulties to pay bills were used as covariates because these variables could have effects on the perception of barriers to PA (Imai and Ratkovic 2014). The difficult to pay bills in the last year (most of the time, from time to time, or never) was included to control for the relative population's purchasing power and household incomes. Percentage of the report each PA barrier across social class and gender was calculated in the matching-physically inactive sample. Finally, logistic regression analyses were run to show the effect of social class on each of the PA barrier's adjusted by propensity score. High social class was the reference.

Those who reported any missing value in IPAQ were excluded from all analyses $(n=787)$. Descriptive analysis was shown as the sample size $(n)$ and percentage (\%), whereas odds ratio (OR) with its $95 \%$ confidence intervals (95\% CI) were calculated for the logistic regression analyses. Statistically, significant differences were considered when $P<0.05$. SPSS 22.0 (SPSS Inc., Chicago, USA) was used to execute all statistical analyses.

\section{Results}

\section{Descriptive analysis}

Table 1 displays the descriptive data of predictor variable across social class and confounders used in a propensity score matching method in the physically active and inactive European populations. Physical inactivity prevalence was higher in women (38.52\%) than men (33.11\%). Regarding age, physical inactivity prevalence was higher according to age. In a similar way, those who never had difficulties paying bills reported fewer prevalence $(32.04 \%)$ to be physically inactive, whereas, by resident place, rural population presented higher inactive prevalence $(38.99 \%)$.

By social stratification, Fig. 1 shows that the low social class population presented the highest physical inactivity prevalence $(43.11 \%)$ and, conversely, the lowest prevalence was found in high social class population $(23.30 \%)$, among which $63.92 \%$ were physically active.
Table 1 Sample size and physical activity prevalence ${ }^{\mathrm{a}}$ in the European Union-28 by covariates employed in propensity score matching method, 2017 Eurobarometer

\begin{tabular}{|c|c|c|c|c|}
\hline & \multicolumn{2}{|c|}{ Inactive } & \multicolumn{2}{|l|}{ Active } \\
\hline & $n$ & $\%$ & $n$ & $\%$ \\
\hline Overall & 9829 & 36.08 & 17,415 & 63.92 \\
\hline \multicolumn{5}{|l|}{ Gender } \\
\hline Male & 4080 & 33.11 & 8241 & 66.89 \\
\hline Female & 5749 & 38.52 & 9174 & 61.48 \\
\hline \multicolumn{5}{|l|}{ Age (years) } \\
\hline $15-24$ & 532 & 23.44 & 1738 & 76.56 \\
\hline $25-34$ & 1014 & 28.81 & 2506 & 71.19 \\
\hline $35-44$ & 1444 & 34.08 & 2793 & 65.92 \\
\hline $45-54$ & 1640 & 36.04 & 2911 & 63.96 \\
\hline $55-64$ & 1776 & 36.10 & 3143 & 63.90 \\
\hline$\geq 65$ & 3423 & 44.18 & 4324 & 55.82 \\
\hline \multicolumn{5}{|l|}{ Resident place } \\
\hline Rural & 3112 & 38.99 & 4870 & 61.01 \\
\hline Small urban & 3142 & 34.70 & 5912 & 65.30 \\
\hline Large urban & 3575 & 35.02 & 6633 & 64.98 \\
\hline \multicolumn{5}{|c|}{ Difficulties paying bills ${ }^{\mathrm{b}}$} \\
\hline Most of the time & 1211 & 49.71 & 1225 & 50.29 \\
\hline From time to time & 2799 & 41.19 & 3997 & 58.81 \\
\hline Never & 5647 & 32.04 & 11,976 & 67.96 \\
\hline
\end{tabular}

anactive population was considered as who do not enough physical activity to meet the WHO guidelines

${ }^{\mathrm{b}}$ In last year

PA barriers percentages among different social class and by gender in the physically inactive population are showed in Fig. 2. The most frequent barriers to PA among women in the high social class were feel discriminated $(85.71 \%)$ and have no time $(57.54 \%)$; and for those in the low social class, to having no friends $(60.87 \%)$, competitivity $(59.89 \%)$, and it is too expensive $(57.14 \%)$. For men, the reasons given were feel discriminated $(55.56 \%)$ in high social class, and lack of motivation $(57.92 \%)$, too expensive $(57.14 \%)$, disability or illness $(56.21 \%)$, and competitivity $(55.17 \%)$ in low social class. Furthermore, low social class group showed a higher prevalence of all PA barriers excepting for "feel discriminated" and "have no time" barriers, that were mainly reported by high social class women and middle social class men, respectively.

\section{Logistic regression analysis}

In the overall population, binomial logistic regression displayed that low and middle social class were less likely to be physically active compared to high social class (as reference) adjusting by gender, age, resident place, and the 


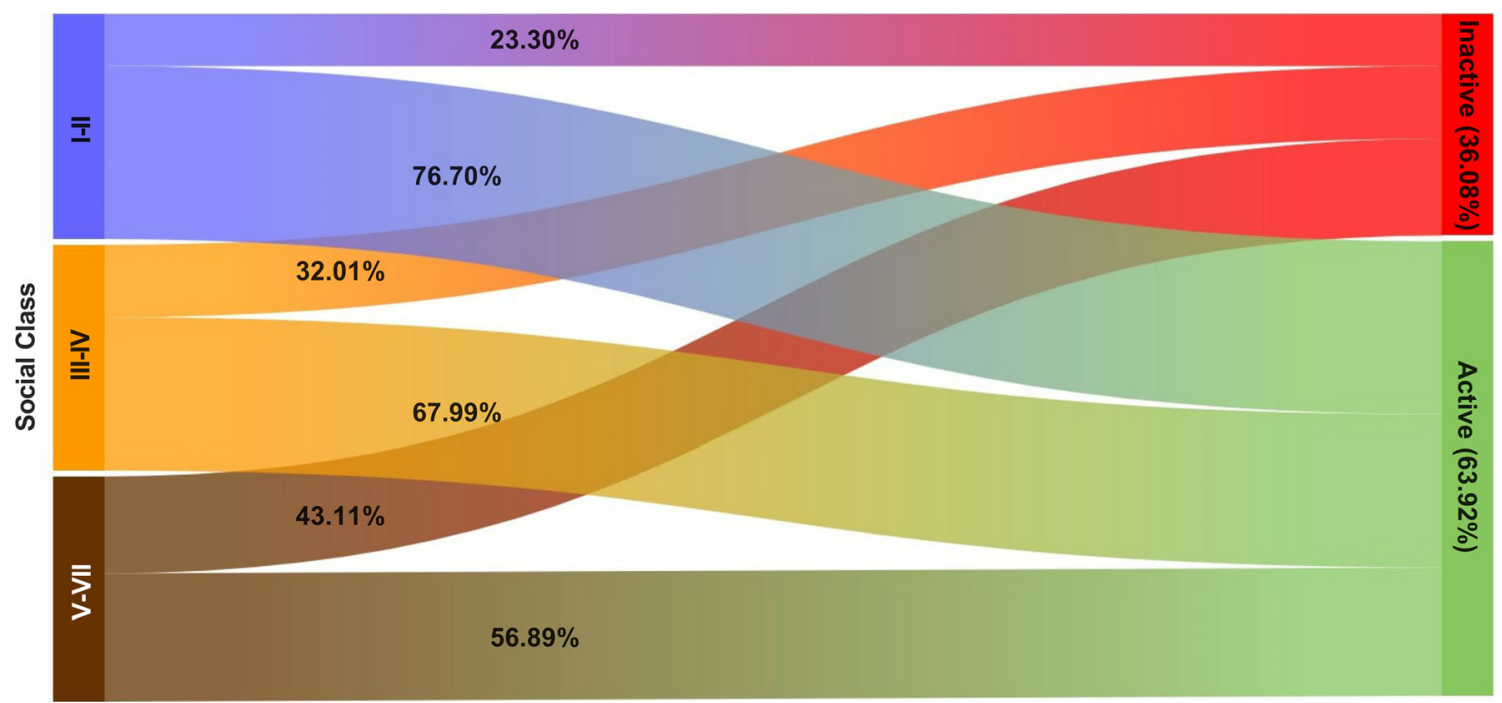

Fig. 1 Physical activity prevalence across social stratification in European Union-28; I-II social class represent high social class $(n=2382)$, IIIIV represent middle social class $(n=12,751)$ and V-VII low social class $(n=11,158), 2017$ Eurobarometer

(a)

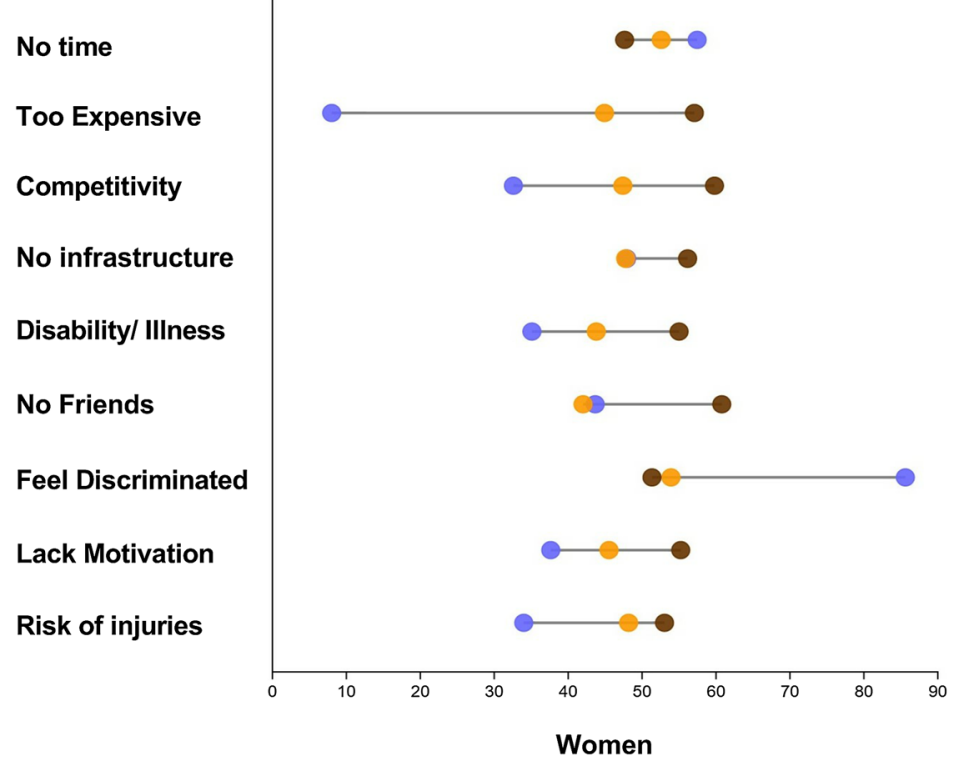

(b)

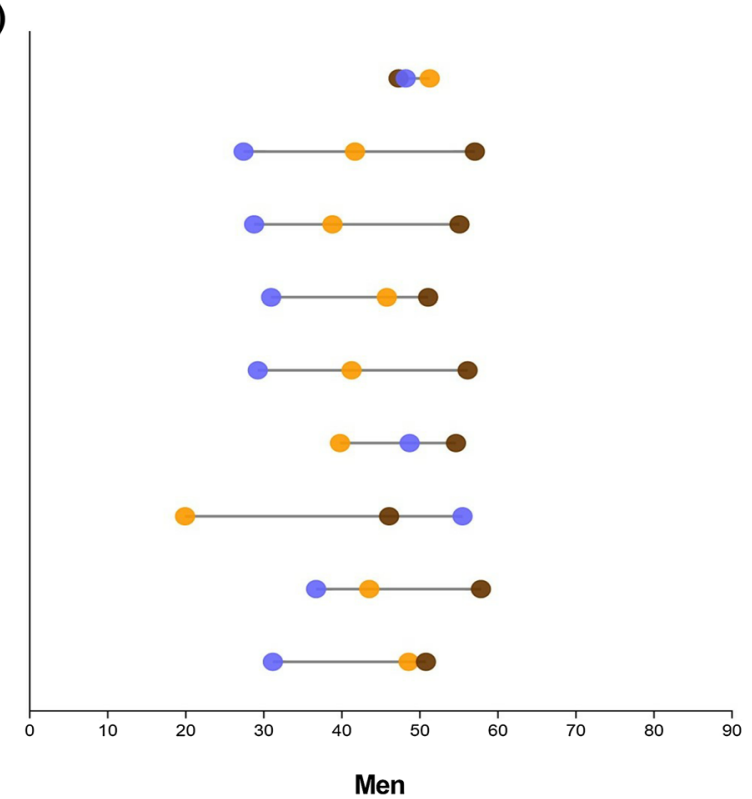

Fig. 2 Percentage of physical activity barriers among high (blue), middle (orange) and low (brown) social class by gender in inactive European population $(n=9829)$, European Union-28, 2017 Eurobarometer (colour figure online)

difficulties to pay bills [(OR $0.52 ; 95 \%$ CI $0.47-0.58$; $P<0.001)$ and (OR 0.71; 95\% CI 0.64-0.79; $P<0.001$ ), respectively].

Regarding the physically inactive population $(n=9829)$ and PA barriers (Table 2; Fig. 3) compared to the high social class, both low and middle social classes were more likely not to practice PA due to its too high price, because of a risk of injury, to have disabilities or any kind of illness, to present a lack of motivation, and owing to competitivity reasons. Besides, the low social class reported higher marginal non-statistically significant likelihood not to practice PA by no infrastructures and was less likely to have no time, whilst middle social class presented lower probability not to practice PA as a result of feeling discriminated against.

Attending to gender, compared to high social class women, low social class women were more likely to have any disability or illness preventing them from exercising, owing to injury risks, to report a lack of motivation and due to competitivity, and were less likely to have no time to practice PA. Besides, both low and middle social class women had higher probabilities to not perform PA owing 
Table 2 Associations between social class and physical activity barriers in inactive population ${ }^{\mathrm{a}}$ in the European Union-28 $(n=9829), 2017$ Eurobarometer

\begin{tabular}{|c|c|c|c|c|c|c|}
\hline & \multicolumn{2}{|l|}{ All } & \multicolumn{2}{|l|}{ Women } & \multicolumn{2}{|l|}{ Men } \\
\hline & OR $(95 \% \mathrm{CI})^{\mathrm{b}}$ & $P$ & OR $(95 \% \mathrm{CI})$ & $P$ & OR $(95 \% \mathrm{CI})$ & $P$ \\
\hline \multicolumn{7}{|l|}{ No time } \\
\hline Low class & $0.59(0.36-0.96)$ & 0.034 & $0.68(0.50-0.93)$ & 0.017 & $0.94(0.70-1.28)$ & 0.706 \\
\hline Middle class & $0.84(0.51-1.39)$ & 0.504 & $0.82(0.60-1.13)$ & 0.224 & $1.12(0.83-1.51)$ & 0.472 \\
\hline \multicolumn{7}{|l|}{ Too expensive } \\
\hline Low class & $5.94(3.26-10.84)$ & $<0.001$ & $15.17(4.59-50.18)$ & $<0.001$ & $3.39(1.61-7.14)$ & 0.001 \\
\hline Middle class & $3.49(1.91-6.37)$ & $<0.001$ & $9.29(2.80-30.80)$ & $<0.001$ & $1.87(0.89-3.93)$ & 0.101 \\
\hline \multicolumn{7}{|l|}{ Competitivity } \\
\hline Low class & $2.72(1.73-4.27)$ & $<0.001$ & $2.73(1.46-5.10)$ & 0.002 & $2.72(1.41-5.27)$ & 0.003 \\
\hline Middle class & $1.72(1.10-2.70)$ & 0.018 & $1.80(0.97-3.34)$ & 0.063 & $1.62(0.84-3.13)$ & 0.151 \\
\hline \multicolumn{7}{|c|}{ No infrastructure } \\
\hline Low class & $1.79(0.99-3.26)$ & 0.055 & $1.42(0.61-3.31)$ & 0.415 & $2.09(0.88-4.97)$ & 0.096 \\
\hline Middle class & $1.39(0.77-2.52)$ & 0.273 & $1.04(0.45-2.40)$ & 0.932 & $1.71(0.72-4.06)$ & 0.225 \\
\hline \multicolumn{7}{|l|}{ Disability/illness } \\
\hline Low class & $2.69(2.03-3.57)$ & $<0.001$ & $2.28(1.51-3.44)$ & $<0.001$ & $3.13(2.11-4.64)$ & $<0.001$ \\
\hline Middle class & $1.60(1.20-2.13)$ & 0.001 & $1.45(0.96-2.20)$ & 0.080 & $1.70(1.13-2.54)$ & 0.010 \\
\hline \multicolumn{7}{|l|}{ No friends } \\
\hline Low class & $1.47(0.88-2.45)$ & 0.137 & $1.92(0.90-4.10)$ & 0.090 & $1.10(0.54-2.22)$ & 0.791 \\
\hline Middle class & $0.80(0.48-1.32)$ & 0.377 & $0.94(0.44-1.20)$ & 0.864 & $0.68(0.34-1.38)$ & 0.284 \\
\hline \multicolumn{7}{|c|}{ Feel discriminated } \\
\hline Low class & $0.34(0.10-1.13)$ & 0.078 & $0.16(0.02-1.53)$ & 0.112 & $0.38(0.07-2.03)$ & 0.257 \\
\hline Middle class & $0.29(0.09-0.94)$ & 0.040 & $0.20(0.02-1.76)$ & 0.145 & $0.15(0.02-0.93)$ & 0.041 \\
\hline \multicolumn{7}{|l|}{ Lack motivation } \\
\hline Low class & $2.15(1.71-2.71)$ & $<0.001$ & $2.02(1.44-2.83)$ & $<0.001$ & $2.32(1.69-3.20)$ & $<0.001$ \\
\hline Middle class & $1.36(1.08-1.71)$ & 0.009 & $1.38(0.98-1.93)$ & 0.063 & $1.32(0.96-1.81)$ & 0.088 \\
\hline \multicolumn{7}{|l|}{ Risk of injuries } \\
\hline Low class & $2.24(1.42-3.55)$ & 0.001 & $2.13(1.11-4.09)$ & 0.023 & $2.29(1.19-4.41)$ & 0.013 \\
\hline Middle class & $1.93(1.22-3.07)$ & 0.005 & $1.78(0.92-3.43)$ & 0.084 & $2.08(1.08-4.01)$ & 0.029 \\
\hline
\end{tabular}

${ }^{a}$ Inactive population was considered as who do not enough physical activity to meet the WHO guidelines

${ }^{\mathrm{b}}$ Reference was high social class. All odds ratio and $95 \%$ confidence intervals are propensity score adjusted

to its too high price. There were also some marginally nonsignificant barriers among middle social class women, such as disability or illness, risk of injury lack of motivation, and competitivity. On the other hand, compared to high social class men, low social class men were more likely to perceive that exercise practice is too expensive, imply an injury risk, not to do PA because of disability or illness, have a lack of motivation, and due to competitivity. Ultimately, middle social class men reported a higher risk of inactivity due to disability or illness reasons, injury risk, and lack of motivation (a marginally non-significant effect for the last one), whereas they had fewer probability to mention feeling discriminated as a PA barrier.

\section{Discussion}

Here we show an important association of social class on PA prevalence and its barriers in over 15-European population. We observed a relatively higher PA prevalence among the middle and high social class population. Among the inactive population, perceived PA barriers were more frequent in those from low social class. Likewise, the likelihood to perceive barriers for PA were higher in low social class than middle social class at most barriers using high social class as the reference. The low social class more frequently experienced the following PA barriers: too expensive to practice, due to competitivity, have disabilities or illness, and injury risk. 
(a)

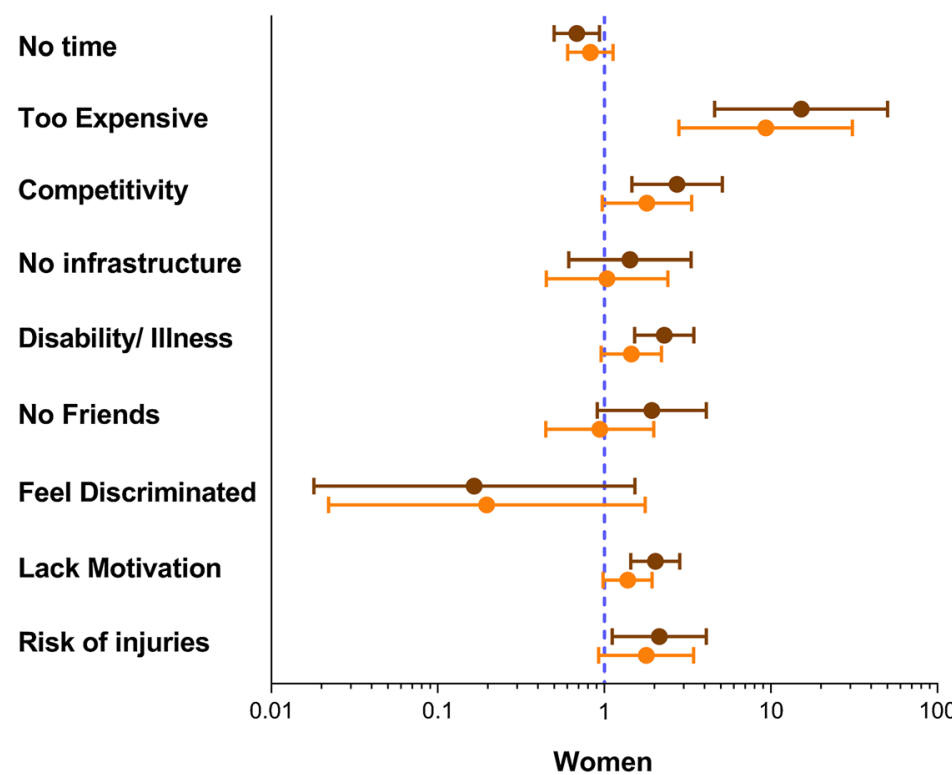

(b)

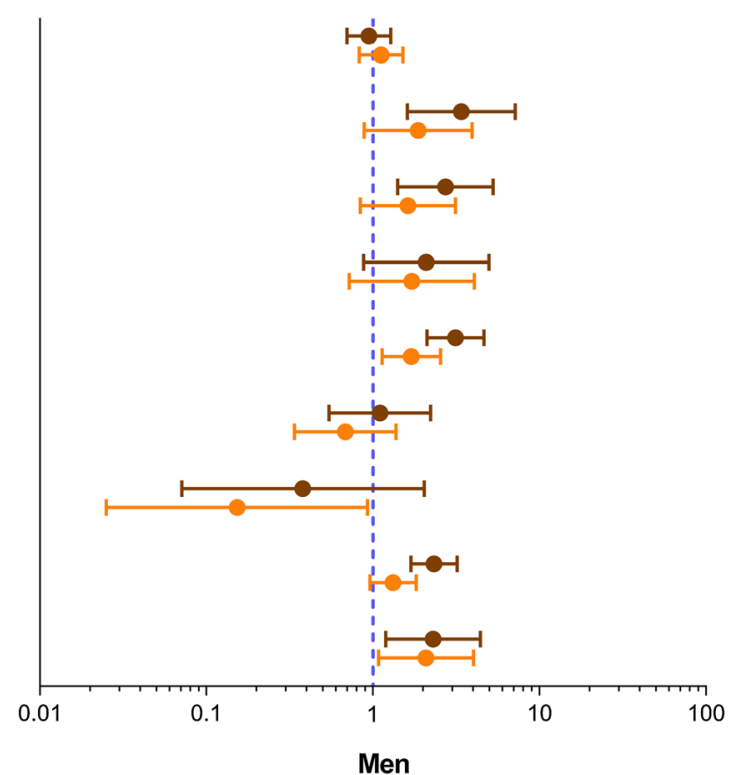

Fig. 3 Physical activity barriers in middle (orange) and low (brown) social class by gender in inactive European population $(n=9829)$; Results are presented as Odds ratios and 95\% Confidence Intervals

These findings are consistent with several similar studies addressing PA prevalence across socioeconomic status (SES) based on incomes. Parks et al. (2003) showed that those who earned lower earnings were more likely to be physically inactive in the USA. Other study led by Popham and Mitchell (2007) also described that adults with lower SES were associated with few or no PA practice, however, when PA was adjusted by employment and health status, the relationship decreased. Another study assessed leisuretime PA (LTPA) prevalence according to social class, using several factors (e.g. education level, incomes, marital status, and employment status), yielding higher probabilities to be physically inactive among low social class population and women in the USA (Marshall et al. 2007).

On the other hand, some studies have examined associations among LTPA and PA barriers. One of these researchers found that non-practice of LTPA was correlated with a lack of motivation followed by poor health and lack of facilities in Australian adults (Cerin et al. 2010). Moreover, a cross-sectional study in Brazil showed a lack of money as a remarkable important barrier, especially in women who also described a stronger relationship to present all barriers, excluding the risk of injuries, whereas wealth status was conversely related with this lack of money and injury risk (Reichert et al. 2007). Regarding how PA barriers could vary across SES, it seems that a lower status tended to present more barriers, which also differ according to the socioeconomic gradient. Some of these studies are qualitative and are mainly focused on (base 10 logarithmic scale). Reference group was high social class, Europe Union-28, 2017 Eurobarometer (colour figure online)

older adults: A focus group in Brazilian elder women showed that those with higher SES present lack of social support, routine obstacles, the weather, social isolation, and because of poor health as barriers, whereas those with lower SES cited the costs, routine obstacles, household tasks, lack of time, and safety (Añez et al. 2011); another focus group study in Northern Irish older adults yield that the lack of time, facilities, and transport are the more frequent barriers with a high SES, but health conditions, neighbourhood safety, and also the lack of facilities to practice PA were more prone among with a low SES (Gray et al. 2016). In cross-sectional studies, the evidence is quite similar with higher barriers also in lower SES groups. Among the more reported PA barriers in the high SES group are lack of time and motivation; otherwise, and in the low SES group, disabilities, illnesses, and the lack of money and transport are often cited (Chinn et al. 1999). Sequeira et al. (2011) described that the most influent barriers to not meeting PA recommendations were the desire to do other things in high SES; and the costs, lack of time, and infrastructures in low SES; as well as the lack of time were the most reported barrier regardless SES. Our results agree with others reporting the importance of the lack of time and motivation, lack of money, and disabilities and illnesses among the lower social class. However, given that the EU-28 is comprised by high-income countries, our findings might not be extrapolated to low- and middleincome countries where social class differences are slight and not so remarkable, with clear disadvantages in the 
overall population. Thus, PA motives and barriers might differ, or even other determinants could be more important for physical inactivity. Furthermore, our study also has inherent limitations.

\section{Study limits}

This work has several limitations owing to the intrinsicmethodological properties of the study: being a cross-sectional study, a cause-effect relationship cannot be established, only establishing association among the social class, PA prevalence, and barriers. Also, PA assessment using IPAQ have disadvantages because this instrument is based on self-reported values, implying recall or memory biases, and social convenience bias that might under- or over-estimate PA level. Another IPAQ's bias could be reactivity response by social convenience with the interviewer overestimating PA. Moreover, most daily activity is performed at light intensities, which is difficult to recall. Despite this, IPAQ has been specifically validated for large sample size studies (Craig et al. 2003). Barriers reported in other studies that are missing here, such as transport and accessibility to determined places, could also be relevant to address daily light PA, which represents a relevant part of weekly PA. We were not able to use educational level as a potential confounder, as a high education level could prevent harmful lifestyle and health-related behaviours as physical inactivity (Parks et al. 2003; Marshall et al. 2007; Popham and Mitchell 2007), although a higher educational level is more frequent in those people from middle and high social class. Also, incomes were only controlled by the difficulty to pay bills, despite that the difficulty to pay bills could be considered a good approach to establish a relative assessment of individual income.

\section{Implications}

Inactivity prevalence has increased in the European population during recent years, and it is expected to increase worldwide in the near future. To reverse this trend, health institutions should increase active lifestyle promotion and information policies according to population needs and characteristics. Those reporting less PA and experiencing more barriers are women, older adults, and low social class groups. Our study shows that effective strategies should pay special attention to a more vulnerable population, taking into account social inequalities according to the reasons why people cannot do regular PA. These measures must be available for those of all social classes and economic statuses. For instance, PA could be promoted in low social class and deprived population groups by reducing the costs and/or applying incentives for the use of sports infrastructures, as well as to join sport club or fitness centre, as other studies have already suggested (Chinn et al. 1999). Moreover, these types of activities should be conducted under the supervision of exercise professionals, which may boost safety, self-confidence, and motivation to generate adherence, thereby increasing PA levels. Lack of time could be related to relevant aspects, such as labour conditions, active transport, accessibility and proximity to basic services, and place of work. Measures based on improving and increasing proximity and implementing cycling and improving public transport might increase daily PA. Also, these actions might benefit all social classes as regards to the lack of time to meet PA recommendations. On the assumption that physical inactivity continues rising, global health related to PA will decline with an NCDs advance and, beyond health domains, also with a considerable economic impact on medical systems and companies (Ding et al. 2016).

\section{Future research}

Further research is needed to better understand why certain groups are more prone to inactivity, as well as to implement successful and effective measures that enhance PA levels, or at least, to slow the rate of inactivity increase. Subsequently, these strategies must be monitored and evaluated across time to establish their effectiveness, using longitudinal-cohort studies, with special attention to how people experience PA barriers, and how these barriers change in the long-term.

\section{Conclusion}

More than one-third of the European population is inactive. We have found that there is a social class stratification in PA levels and PA barriers, with higher inactivity prevalence in those from a low social class that also experience more barriers. Here, we highlight how people from low social class more frequently report barriers as too high price, have disability or illness, injury risk, and competitivity. Important PA promotion strategies in the overall population are needed, especially focused on these barriers, among low social class and more vulnerable groups in the European population.

Funding None.

\section{Compliance with ethical standards}

Conflict of interest The authors declare that they have no conflicts of interest.

Ethical approval Not applicable. 
Informed consent Not applicable.

\section{References}

Añez R et al (2011) Barriers to physical activity among Brazilian elderly women from different socioeconomic status: a focusgroup study. J Phys Act Heal 8:126-132

Bauman AE, Reis RS, Sallis JF et al (2012) Correlates of physical activity: Why are some people physically active and others not? Lancet 380:258-271. https://doi.org/10.1016/S01406736(12)60735-1

Cerin E, Leslie E, Sugiyama T, Owen N (2010) Perceived barriers to leisure-time physical activity in adults: an ecological perspective. J Phys Act Heal 7:451-459. https://doi.org/10.1123/jpah.7. 4.451

Chan TW, Goldthorpe JH (2007) Class and status: the conceptual distinction and its empirical relevance. Am Sociol Rev 72:512-532. https://doi.org/10.1177/000312240707200402

Chinn DJ, White M, Harland J et al (1999) Barriers to physical activity and socioeconomic position: implications for health promotion. J Epidemiol Community Health 53:191-192. https:// doi.org/10.1136/jech.53.3.191

Costello E, Kafchinski M, Vrazel J, Sullivan P (2011) Motivators, barriers, and beliefs regarding physical activity in an older adult population. J Geriatr Phys Ther 34:138-147. https://doi.org/10. 1519/JPT.0b013e31820e0e71

Craig CL, Marshall AL, Sjöström M et al (2003) International physical activity questionnaire: 12-Country reliability and validity. Med Sci Sports Exerc 35:1381-1395. https://doi.org/ 10.1249/01.MSS.0000078924.61453.FB

Denman S (1998) The sociology of health promotion; critical analyses of consumption, lifestyle and risk. J Public Health 20:115. https://doi.org/10.1093/oxfordjournals.pubmed.a024703

Ding D, Lawson KD, Kolbe-Alexander TL et al (2016) The economic burden of physical inactivity: a global analysis of major noncommunicable diseases. Lancet 388:1311-1324. https://doi.org/ 10.1016/S0140-6736(16)30383-X

Domingo-Salvany A, Bacigalupe A, Carrasco JM et al (2013) Propuestas de clase social neoweberiana y neomarxista a partir de la Clasificación Nacional de Ocupaciones 2011. Gac Sanit 27:263-272. https://doi.org/10.1016/j.gaceta.2012.12.009

European Commission (2018) Eurobarometer 88.4 (2017). TNS opinion, Brussels. In: GESIS Data Arch. Col. https://doi.org/10. 4232/1.13065

Gray PM, Murphy MH, Gallagher AM, Simpson EEA (2016) Motives and barriers to physical activity among older adults of different socioeconomic status. J Aging Phys Act 24:419-429. https://doi. org/10.1123/japa.2015-0045

Guthold R, Stevens GA, Riley LM, Bull FC (2018) Worldwide trends in insufficient physical activity from 2001 to 2016: a pooled analysis of 358 population-based surveys with 1.9 million participants. Lancet Glob Heal 6:e1077-e1086. https://doi.org/ 10.1016/S2214-109X(18)30357-7

Hallal PC, Bauman AE, Heath GW et al (2012) Physical activity: more of the same is not enough. Lancet 380:190-191. https://doi. org/10.1016/S0140-6736(12)61027-7

Huijts T, Stornes P, Eikemo TA et al (2017) The social and behavioural determinants of health in Europe: findings from the European Social Survey (2014) special module on the social determinants of health. Eur J Public Health 27:55-62. https://doi. org/10.1093/eurpub/ckw231

Imai L, Ratkovic M (2014) Covariate balancing propensity score. J R Stat Soc Ser B 76:243-263. https://doi.org/10.1111/rssb.12027

Kelly S, Martin S, Kuhn I et al (2016) Barriers and facilitators to the uptake and maintenance of healthy behaviours by people at midlife: a rapid systematic review. PLoS ONE 11:e0145074. https:// doi.org/10.1371/journal.pone.0145074

Kohl HW, Craig CL, Lambert EV et al (2012) The pandemic of physical inactivity: global action for public health. Lancet 380:294-305. https://doi.org/10.1016/S0140-6736(12)60898-8

Marshall SJ, Jones DA, Ainsworth BE et al (2007) Race/ethnicity, social class, and leisure-time physical inactivity. Med Sci Sports Exerc 39:44-51. https://doi.org/10.1249/01.mss.0000239401. 16381.37

O’Donoghue G, Kennedy A, Puggina A et al (2018) Socio-economic determinants of physical activity across the life course: a "DEterminants of DIet and Physical ACtivity" (DEDIPAC) umbrella literature review. PLoS ONE 13:e0190737

Parks SE, Housemann RA, Brownson RC (2003) Differential correlates of physical activity in urban and rural adults of various socioeconomic backgrounds in the United States. J Epidemiol Community Health 57:29-35. https://doi.org/10. 1136/jech.57.1.29

Popham F, Mitchell R (2007) Relation of employment status to socioeconomic position and physical activity types. Prev Med (Baltim) 45:182-188. https://doi.org/10.1016/j.ypmed.2007.06. 012

Reichert FF, Barros AJD, Domingues MR, Hallal PC (2007) The role of perceived personal barriers to engagement in leisure-time physical activity. Am J Public Health 97:515-519. https://doi. org/10.2105/AJPH.2005.070144

Rhodes RE, Janssen I, Bredin SSD et al (2010) Physical activity: health impact, prevalence, correlates and interventions. Psychol Heal 32:942-975. https://doi.org/10.1080/08870446.2017. 1325486

Rubin DB, Rosenbaum PR (1983) The central role of the propensity studies for causal effects. Biometrika 70:41-55. https://doi.org/ 10.1093/biomet/70.1.41

Rutter H, Cavill N, Bauman A, Bull F (2019) Systems approaches to global and national physical activity plans. Bull World Health Organ 97:162-165. https://doi.org/10.2471/blt.18.220533

Sequeira S, Cruz C, Pinto D et al (2011) Prevalence of barriers for physical activity in adults according to gender and socioeconomic status. Br J Sports Med 45:A18-A19. https://doi.org/10. 1136/bjsports-2011-090606.59

STROBE Statement (2008) STROBE Statement-checklist of items that should be included in reports of observational studies ${ }^{1}$ (C) STROBE Initiative). Int J Public Health 53:3-4. https://doi.org/ 10.1007/s00038-007-0239-9

Wilmot EG, Edwardson CL, Achana FA et al (2012) Sedentary time in adults and the association with diabetes, cardiovascular disease and death: systematic review and meta-analysis. Diabetologia 55:2895-2905. https://doi.org/10.1007/s00125-012$2677-\mathrm{z}$

World Health Organization (2010) Global recommendations on physical activity for health. World Health Organization, Geneva

Publisher's Note Springer Nature remains neutral with regard to jurisdictional claims in published maps and institutional affiliations. 